\title{
Surgical revascularization in women: Unique intraoperative factors and considerations
}

\author{
Jennifer S. Lawton, MD \\ Stephanie J. Brister, MD \\ Kathleen R. Petro, $\mathrm{MD}^{\mathrm{C}}$ \\ Mercedes Dullum, MD ${ }^{\mathrm{c}}$
}

See related articles on pages $929,932,950$, and 959 .

From the Washington University School of Medicine, ${ }^{\text {a }}$ St Louis, Mo; the University of Toronto, ${ }^{\mathrm{b}}$ Toronto, Ontario, Canada; and the Washington Hospital Center, ${ }^{\mathrm{c}}$ Washington, DC.

Received for publication March 25, 2003; revisions requested April 8, 2003; revisions accepted April 18, 2003; accepted for publication April 24, 2003.

Address for reprints: Jennifer S. Lawton, MD, One Barnes Jewish Hospital Plaza, Queeny Tower Suite 3108, St Louis, MO 63131 (E-mail: lawtonj@msnotes.wustl. edu).

J Thorac Cardiovasc Surg 2003;126:936-8

Copyright (๑) 2003 by The American Association for Thoracic Surgery

$0022-5223 / 2003 \$ 30.00+0$

doi:10.1016/S0022-5223(03)00805-5

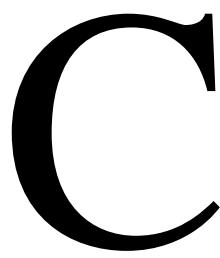

ardiovascular disease (CVD) is the leading cause of morbidity and mortality for women in the United States, Canada, and most developed countries. In developing countries it will be the leading cause of death in the next 20 years. It is a costly disease both in terms of health care dollars spent and patient lives. Approximately 250,000 women die each year in the United States, and women are 3 times as likely to die of CVD as they are of breast cancer. ${ }^{1}$ With the publication 10 years ago of 2 sentinel studies detailing the differences between men and women in the delivery of care to patients with CVD, there has been an increased awareness in the health care community and the lay public of issues relevant to the assessment and management of CVD in women. ${ }^{2,3}$ Perception of CVD by both communities is still evolving and is often influenced by insufficient or, worse, inaccurate information. The androcentric focus of much of cardiovascular research contributes to this problem. Only recently have women been included in sufficient numbers in clinical trials and databases or has there been a requirement for sex-based analysis of data such that specific information pertaining to results in women has been available..$^{3-5}$ The problem is compounded when trying to analyze the results of coronary artery bypass grafting $(\mathrm{CABG})$ in women because only $30 \%$ of all $\mathrm{CABG}$ operations are performed on women and fewer women than men are referred for operation, resulting in small sample sizes. ${ }^{6}$

Numerous studies have demonstrated increased hospital mortality after CABG in women when compared with men. ${ }^{7-9}$ Increased mortality in women in these studies has often been attributed to referral bias, smaller vessels, decreased body size, and an increased incidence of comorbidities. ${ }^{10-13}$ More recently, studies suggest that despite the obvious premorbid differences between men and women, women still clearly benefit from surgical revascularization. ${ }^{13,14}$ Despite good long-term results for women undergoing $\mathrm{CABG}$, misperception of results still clearly influences their surgical treatment. For example, proportionally fewer women receive arterial grafts or reoperation. ${ }^{11,13,15,16} \mathrm{We}$ review the intraoperative factors and considerations that are unique to women facing $\mathrm{CABG}$ in an attempt to raise awareness and to support the use of surgical revascularization in women.

\section{Technical Aspects of CABG}

Despite advances in cardiopulmonary bypass and postoperative care that appear to have reduced perioperative mortality in men, the perioperative mortality after CABG in women remains twice that of men. ${ }^{17}$ Women experience a longer time to diagnosis, treatment, and referral to invasive testing. ${ }^{5,18}$ Women appear to have more acute presentations, are 10 years older on presentation, and have multiple comorbidities when compared with men. One recent editorial suggests that increased perioperative mortality might be related to a higher incidence of left ventricular hypertrophy and hypertensive heart disease in women. ${ }^{19}$ However, when comorbidities are adjusted for by using multivariate models, women still face a significantly higher operative risk when compared with that faced by men. ${ }^{17}$ 
Therefore there must be some other perioperative variable that we do not appreciate that accounts for this increased mortality.

We should therefore consider several intraoperative factors as they apply to women. The use of cardioplegia and cardiopulmonary bypass and the administration of cardioplegia should be evaluated carefully. A decrease in mortality and morbidity in women undergoing $\mathrm{CABG}$ without cardiopulmonary bypass has been suggested. ${ }^{20}$ Mortality in women undergoing off-pump CABG was equivalent to expected mortality in men undergoing on-pump CABG in one study (2.3\% for off-pump CABG and $4.1 \%$ for on-pump CABG in women) ${ }^{20}$ In a recent study of 16,871 consecutive women undergoing off-pump and on-pump CABG surgery at 78 hospitals between January 1998 and June 2001, offpump CABG in women was associated with a reduction in mortality and morbidity. ${ }^{21}$ The reason for the reduction in mortality in women for off-pump surgery is not easily determined. It is best determined by means of randomized controlled comparisons. This study is not likely to be completed in the near future. Until the cause of increased perioperative mortality in women is determined, off-pump revascularization should be an essential option in the surgeon's armamentarium, particularly for women. Optimal and complete revascularization can easily be accomplished without cardiopulmonary bypass. The approach to successful off-pump CABG is the same for all cardiac surgeries and requires planning, patience, and attention to detail.

Women more frequently present or come to the operation with ongoing ischemia or with acute presentations. It is important to consider this when determining the optimal administration of cardioplegia in women who undergo CABG on pump. In the setting of acute ischemia, warm induction cardioplegia should be considered, as well as warm reperfusion. In addition, the use of hemofiltration during cardiopulmonary bypass should be considered in women who are more likely to have congestive heart failure and volume overload preoperatively.

Use of the left internal thoracic artery (LITA) to the left anterior descending artery (LAD) has clearly been shown to be superior to use of the saphenous vein to revascularize the LAD. Even though there is clear benefit, women still receive fewer LITA grafts than men, and this choice is not dependent on the urgency of the operation or the prevalence of diabetes. The use of radial artery grafting has not been specifically evaluated in women. Although the use of bilateral internal thoracic artery grafts has been demonstrated to be safe in women, the benefit of bilateral internal thoracic artery use compared with a single internal thoracic artery has not been documented. ${ }^{22}$ Women should receive a LITA graft to the LAD and use of the radial artery as first choices of conduit, as well as attempts to make surgical revascular- ization complete, to gain the same benefit from $\mathrm{CABG}$ as their male counterparts.

Numerous studies have cited smaller coronary artery size and resultant increased technical challenge as the major factor responsible for increased mortality in women undergoing CABG. ${ }^{23}$ There is no doubt that women have smaller body surface areas and coronary sizes, as has been demonstrated by many investigators. ${ }^{24}$ There are 2 arguments that suggest that smaller coronary size is not the major factor responsible for increased mortality in women. The first is that in the data available, mortality for women who undergo off-pump CABG is equivalent to that of men. If women have smaller coronary arteries, then off-pump CABG would be that much more technically challenging. Therefore offpump CABG mortality would intuitively be much higher in women, which is not the case. The second is that the mortality in women undergoing $\mathrm{CABG}$ decreases with aging. The mortality difference between men and women is greatest in the age range of less than 50 years, and in older women mortality is equivalent to that of men. ${ }^{17}$ Obviously, coronary arteries do not get larger with age. Therefore small coronary artery size cannot be the major factor in the mortality difference between men and women.

When considering the inability to wean from cardiopulmonary bypass in women, inotrope use must be weighed with the use of an intra-aortic balloon pump. Women pose unique risks to the use of intra-aortic balloon pump because of smaller body and femoral artery size and an increased likelihood of having peripheral vascular disease. Smaller balloon and catheter sizes should obviously be chosen to reduce the likelihood of complications.

\section{Summary}

The bad news is that CVD is the number one killer of women, and the number of deaths in women has surpassed that in men since $1984 .{ }^{1}$ Women do not perceive this threat, and they might present with atypical symptoms, making diagnosis difficult. When compared with men, women are less likely to be referred for invasive testing and less likely to receive proved efficacious medications ( $\beta$-blockers, aspirin, and thrombolytics). ${ }^{5}$ Women are more likely to present at an older age (10 years older), to present with sudden death, and to die from their first myocardial infarction and are more likely to have multiple comorbidities when compared with men. The increased operative mortality noted when women undergo CABG on pump is multifactorial and might be related to patient size, comorbidities, treatment conservatism, and other unknown contributing factors.

Fortunately, the good news is that women benefit from surgical revascularization and have similar long-term results when compared with men. There is hope that equivalent short-term outcomes can be achieved with the use of off- 
pump CABG. Until the reasons for increased operative mortality in women are elucidated, we should remain advocates for public education and awareness and risk factor modification, include more women in research and clinical trials, maintain an aggressive approach for women, and support CABG as a valuable and beneficial treatment option.

\section{The Use of the Terms "Sex" and "Gender"}

When addressing differences between women and men, every effort should be made to use correct terminology. The authors of the Institute of Medicine report entitled "Exploring the biological contributions to human health: Does sex matter?" point out that the interchangeable use of "sex" and "gender" causes confusion in the scientific community. ${ }^{25}$ They also note that consistent usage across disciplines would aid in the accurate measurement and reporting of differences between men and women. They offer the following recommendations:

1. In the study of human subjects, the term "sex" should be used as a classification, generally as male or female, according to the reproductive organs and functions that derive from the chromosomal complement.

2. In the study of human subjects, the term "gender" should be used to refer to a person's self-representation as male or female or how that person is responded to by social institutions on the basis of the individual's gender presentation.

3. In most studies of nonhuman animals, the term "sex" should be used.

We have attempted to adhere to these recommendations in this editorial to provide consistency and clarity.

\section{References}

1. American Heart Association Web site. Available at: www.women. americanheart.org.

2. Ayanian JZ, Epstein AM. Differences in the use of procedures between women and men hospitalized for coronary heart disease. $N$ Engl J Med. 1991;325:221-5.

3. Steingart RM, Packer M, Hamm P, Coglianese ME, Gersh B, Geltman EM, et al. Sex differences in the management of coronary artery disease. N Engl J Med. 1991;325:226-30.

4. Stone PH, Thompson B, Anderson H, Kronenberg MW, Gibson RS, Rogers WJ, et al. Influence of race, sex and age in management of unstable angina and non-Q wave myocardial infarction. JAMA. 1996; 275(14):1104-12.

5. Chandra NC, Ziegelstein RC, Rogers WJ. Observations of the treatment of women in the United States with myocardial infarction. Arch Intern Med. 1998;158:981-8.

6. Slaughter PM, Bondy SJ. Women and ischemic heart disease: differences in access to care. Can J Cardiol. 2001;17(suppl D):63D-7D.

7. Tyras DH, Barner HB, Kaiser GC, Codd JE, Laks H, Willman VL.
Myocardial revascularization in women. Ann Thorac Surg. 1978;25: 449-53.

8. Loop FD, Golding LR, MacMillan JP, Cosgrove DM, Lytle BW, Sheldon WC. Coronary artery surgery in women compared with men: analysis of risk and long term results. J Am Coll Cardiol. 1983;1:38390.

9. Gardner TJ, Horneffer PJ, Gott VL, Watkins L Jr, Baumgartner WA, Borkon AM, et al. Coronary artery bypass grafting in women. Ann Surg. 1985;201:780-4.

10. Khan SS, Nessim S, Gray R, Czer LS, Chaux A, Matloff I. Increased mortality of women in coronary artery bypass surgery: evidence for referral bias. Ann Intern Med. 1990;112:561-7.

11. Edwards FH, Carey JS, Grover FL, Bero JW, Hartz RS. Impact of gender on coronary bypass operative mortality. Ann Thorac Surg. 1998;66:125-31.

12. O'Connor GT, Morton JR, Diehl MJ, Olmstead EM, Loffin LH, Levy DG, et al. Differences between men and women in hospital mortality associated with coronary artery bypass graft surgery. Circulation. 1993;88:2104-10.

13. Mickleborough, LL, Takagi Y, Mariyama H, Sun Z, Mohamed S. Is sex a factor in determining operative risk for aortocoronary bypass surgery? Circulation. 1995;92(suppl I):II80-4.

14. Herlitz J, Brandrup-Wognsen G, Karlson BW, Sjoland H, Karlsson T, Caidahl K, et al. Mortality, risk indicators of death, mode of death and symptoms of angina pectoris during 5 years after coronary artery bypass grafting in men and women. J Intern Med. 2000;247:500-6.

15. Hammar N, Sandberg E, Larsen FF, Ivert T. Comparison of early and late mortality in men and women after isolated coronary artery bypass surgery in Stockholm, Sweden 1980-1989. J Am Coll Cardiol. 1997; 29(3):659-64.

16. Jacobs AK, Kelsey SF, Brooks MM, Faxon DP, Chaitman BR, Bittner $\mathrm{V}$, et al. Better outcome for women compared with men undergoing coronary revascularization: a report from the Bypass, Angioplasty, Revascularization Investigation (BARI). Circulation. 1998;98:127985 .

17. Vaccarino V, Abramson JL, Veledar E, Weintraub WS. Sex differences in hospital mortality after coronary artery bypass surgery. Circulation. 2002;105:1176-81.

18. Tsang TS, Barnes ME, Gersh BJ, Hayes SN. Risks of coronary heart disease in women: current understanding and evolving concepts. Mayo Clin Proc. 2000;75(12):1289-303.

19. Jacobs AK. Coronary revascularization in women in 2003: sex revisited. Circulation. 2003;107:375-7.

20. Petro KR, Dullum MK, Garcia JM, Pfister AJ, Qazi AG, Boyce SW, et al. Minimally invasive coronary revascularization in women: a safe approach for a high-risk group. Heart Surg Forum. 2000;3:41-6.

21. Brown PP, Mack MJ, Simon AW, Battaglia S, Tarkington L, Horner $\mathrm{S}$, et al. Outcomes experience with off-pump coronary artery bypass surgery in women. Ann Thorac Surg. 2002;74:2113-20.

22. Kurlansky PA, Traad EA, Galbut DL, Zucker M, Ebra G. Efficacy of single versus bilateral internal mammary artery grafting in women: a long-term study. Ann Thorac Surg. 2001;71:1949-58.

23. Fisher LD, Kennedy JW, Davis KB, Maynard C, Fritz JK, Kaiser G, et al. Association of sex, physical size, and operative mortality after coronary artery bypass in the Coronary Artery Surgery Study (CASS). J Thorac Cardiovasc Surg. 1982;84:334-41.

24. Kucher N, Lipp E, Schwerzmann M, Zimmerli M, Allemann Y, Seiler C. Gender differences in coronary artery size per $100 \mathrm{~g}$ of left ventricular mass in a population without cardiac disease. Swiss Med Wkly. 2001;131:610-5.

25. Pardue M. The future of research on biological sex differences: challenges and opportunities. In: Wizeman TM, Pardue M, editors. Exploring the biological contributions to human health: does sex matter? The National Academies Press; 2001. p. 173-84. Available at: www.nap.edu/books/0309072816/html/. 